\title{
The comparison of traditional vascular risk factor between hemorrhagic and non-hemorrhagic stroke
}

\author{
Rizaldy Taslim Pinzon ${ }^{1}$, Rosa De Lima Renita Sanyasi ${ }^{2}$, Andre Dharmawan Wijono ${ }^{3}$ \\ ${ }^{1}$ Senior Lecturer, Duta Wacana Christian University School of Medicine Yogyakarta, Indonesia, ${ }^{2}$ Internship Doctor, \\ Dr. Efram Harsana Air Force Hospital, Madiun, East Java Indonesia, ${ }^{3}$ Research Assistant, Duta Wacana Christian \\ University School of Medicine Yogyakarta, Indonesia
}

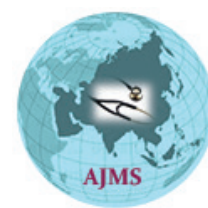

A B S TR A C T

\begin{abstract}
Background: Understanding about risk factors of stroke based on its pathology is very important. Previous study about the vascular risk factors in patients with stroke in Indonesia is very limited. Aims and Objective: Measure the comparison between traditional vascular risk factors in patients with hemorrhagic stroke and non-hemorrhagic (ischemic) stroke. Materials and Methods: This was a nested case-control study using secondary data from electronic medical record and electronic stroke registry of Bethesda Hospital Yogyakarta Indonesia. The stroke was diagnosed with standard way by well-trained neurologist and confirmed with CT Scan. The traditional risk factors were defined systematically. We used Dupont Power and Sample Size calculation software and StatCal Epilnfo software with significance level 0,05. Result: The data of 200 subjects consisted of 100 patients with hemorrhagic stroke and 100 patients with non-hemorrhagic stroke. Hypertension was main vascular risk factor in both Group but it was more common in hemorrhagic stroke (OR: 2,528, 95\% Cl: 0,069;0,316, $\mathrm{p}<0,002)$. Dyslipidemia was a protective factor against hemorrhagic stroke (OR: 0,147,95\% Cl: 1,415; 4,516, p < 0,001). Diabetes was more common in ischemic stroke compared with hemorrhagic stroke (68\% and $32 \%)$ respectively. Conclusion: Hypertension, dyslipidemia, and diabetes were modifiable traditional vascular risk factors which significantly had effect on stroke.
\end{abstract}

Access this article online

Website:

http://nepjol.info/index.php/AJMS DOI: 10.3126/ajms.v8i6.18277 E-ISSN: 2091-0576

P-ISSN: 2467-9100

Key words: Ischemic stroke, Hemorrhagic stroke, Age, Hypertension, Dyslipidemia,

Diabetes

\section{INTRODUCTION}

Stroke is the leading cause of death and disability worldwide ${ }^{1}$ and one of the main causes of adult acquired disabilities. ${ }^{2}$ The World Health Organization (WHO) estimates that there were 6.7 million stroke-related deaths in 2012. This comprised $11.9 \%$ of all deaths which was the second highest cause of death worldwide. ${ }^{3}$ The uncontrolled risk factors correlated with the high incidence of stroke. The understanding about the risk factors and its management need to be used to design strategies to prevent both primary and secondary stroke. ${ }^{4}$ The traditional vascular risk factors are older age, hypertension, diabetes, heart disease/atrial fibrillation, and dyslipidemia. ${ }^{5}$
The understanding about comparison between each risk factor will help physicians to make a good decision in managing the disease. ${ }^{6}$ Previous studies showed that dyslipidemia are more common in patients with ischemic stroke. Hypertension is very common either in hemorrhagic and ischemic stroke. Atrial fibrillation is major risk factor for disabling ischemic stroke. ${ }^{5,7}$

The previous studies showed that inappropriate management of risk factors would lead to high recurrence, higher mortality rate, and disability. ${ }^{6,8}$ The studies about stroke risk factor in Indonesia are very limited. The hospital based epidemiological data are limited. The aim of this study was to measure the comparison between traditional 
risk factors among patients with ischemic stroke and hemorrhagic stroke.

\section{MATERIALS AND METHODS}

This was a nested case control study from electronic stroke registry of Bethesda hospital Yogyakarta. The case was patients with hemorrhagic stroke. The control was patients with non-hemorrhagic (ischemic) stroke. The ratio between case and control was 1:1. Both groups were diagnosed by well trained neurologist and the data are confirmed with CT Scan. The sample size calculation was based on Dupont Power and Sample Size Calculation with type 1 error 5\%, power $80 \%$, the proportion of $\mathrm{AF}$ in hemorrhagic stroke is $5 \%$, and the proportion of $\mathrm{AF}$ in ischemic stroke is $20 \% .{ }^{9}, 10$ The calculation showed that minimal sample in each group is 88 .

The vascular risk factors were collected form electronic medical record and electronic stroke registry. The age and sex of the patient are collected from the information in medical record. The hypertension was defined as the blood pressure $>140 / 90$ in more than two visits or in consumption of anti hypertensive medication. The diabetes was defined as fasting glucose level more than $110 \mathrm{mg} / \mathrm{dL}$ or post prandial more than $180 \mathrm{mg} / \mathrm{dL}$, or taking oral anti diabetic/insulin. Dyslipidemia was defined as cholesterol level above $200 \mathrm{mg} / \mathrm{dL}$ or LDL level above $100 \mathrm{mg} / \mathrm{dL}$, or triglyseride level above $150 \mathrm{mg} / \mathrm{dL}$ in fasting condition, or taking fibrate/statin.

The data were presented in descriptive and analytic way. The percentage of each risk factors in either case or control were described. We used OR (Odds Ratio) and $95 \%$ Confidence Interval to show the comparison. We used StatCal software from EpiInfo to calculate the significance level $(\mathrm{p}<0,05 \%)$.

\section{RESULT}

The data were obtained from 200 patients with stroke, consist of 100 subjects with ischemic stroke and 100 hemorrhagic stroke. The characteristic of vascular risk factors in stroke patients are shown in Table 1. Hypertension was main vacular risk factor in both Group but it was more common in hemorrhagic stroke. Diabetes was more common in ischemic stroke. Dyslipidemia was more common in ischemic stroke, while the age and sex were similar in both groups.

The Comparative analysis of traditional risk factors between hemorrhagic and ischemic stroke were shown in Table 2. This study showed that hypertension increased the

\begin{tabular}{|c|c|c|c|}
\hline \multirow[t]{2}{*}{ Variable } & \multicolumn{2}{|c|}{ Stroke N (\%) } & \multirow[t]{2}{*}{ Total N (\%) } \\
\hline & $\begin{array}{l}\text { Hemorrhagic } \\
\text { stroke }\end{array}$ & $\begin{array}{l}\text { Ischemic } \\
\text { stroke }\end{array}$ & \\
\hline \multicolumn{4}{|l|}{ Age } \\
\hline$\leq 60$ years old & $53(57)$ & $40(53)$ & $93(100)$ \\
\hline$>60$ years old & 47 (43.9) & $60(56.1)$ & $107(100)$ \\
\hline \multicolumn{4}{|l|}{ Sex } \\
\hline Male & 53 (46.1) & $62(53.9)$ & $115(100)$ \\
\hline Female & 47 (55.3) & 38 (44.7) & $85(100)$ \\
\hline \multicolumn{4}{|l|}{ Hypertension } \\
\hline Yes & 70 (59.3) & $48(40.7)$ & $118(100)$ \\
\hline No & $30(36.6)$ & $52(63.4)$ & $82(100)$ \\
\hline Diabetes & & $32(68)$ & \\
\hline Yes & $15(32)$ & $68(44.4)$ & $47(100)$ \\
\hline No & 85 (55.6) & & $153(100)$ \\
\hline \multicolumn{4}{|l|}{ Dyslipidemia } \\
\hline Yes & $10(18.9)$ & 43 (81.1) & $53(100)$ \\
\hline No & $90(61.2)$ & 57 (38.8) & $147(100)$ \\
\hline
\end{tabular}

\begin{tabular}{|c|c|c|c|}
\hline Predictors & OR & $95 \% \mathrm{Cl}$ & $p$ \\
\hline Old age & 1.691 & $0.966-2.963$ & 0.065 \\
\hline Male sex & 0.691 & $0.394-1.214$ & 0.198 \\
\hline Hypertension & 2.528 & $1.415-4.516$ & 0.002 \\
\hline Diabetes & 0.375 & $0.187-0.748$ & 0.005 \\
\hline Dyslipidemia & 0.147 & $0.069-0.316$ & 0.001 \\
\hline
\end{tabular}

risk of hemorrhagic stroke compared with ischemic stroke (OR: 2,528, 95\% CI: 0,069; 0,316, p <0,002). Dyslipidemia apparently had a protective factor against hemorrhagic stroke (OR: 0,147, 95\% CI: 1,415; 4,516, p < 0,001).

\section{DISCUSSION}

The main purpose of this study was to measure the comparison between traditional vascular risk factors in patients with hemorrhagic stroke and non-hemorrhagic (ischemic) stroke. This study showed that hypertension is the main risk factors for either hemorrhagic and nonhemorrhagic stroke. Hypertension is a known risk factor for all strokes, and blood pressure control is associated with a reduction of recurrent events. ${ }^{8}$ High blood pressure can lead to occlusive stroke, as well as intracerebral or subarachnoid hemorrhage, and correlates with the risk of first-ever stroke and recurrent stroke. ${ }^{6}$ A Meta analysis study had shown that hypertension affected the incidence of stroke in all subtypes in Western and Chinese Population (HR:1.79, 95\% CI:1.39;2.30, $\mathrm{p}=0.000$ ) and (HR: 2.84, 95\% CI: 2.10;3.82, $\mathrm{p}=0.000$ ) respectively. ${ }^{11}$ Similarly, previous studies have found that there is a wellestablished relationship between hypertension and the risk for developing stroke in all subtypes. ${ }^{12,13}$ 
The proportion of hypertension in hemorrhagic stroke patients was significantly higher compared with nonhemorrhagic stroke patients (59.3\%) and (40.7\%) respectively (Table 1). The comparative analysis in this study also showed that hypertension increase the risk of hemorrhagic stroke compared with ischemic stroke. Previous study showed that hypertension contributes to the majority of primary intracerebral hemorrhages. Numerous studies document this relationship, and it is consistent throughout America, Europe, and the AsiaPacific region. ${ }^{7}$ Similarly, a previous case control studies found that hypertension was the most important risk factor for all stroke subtypes, and a more potent risk factor for intracerebral haemorrhagic stroke than for ischaemic stroke and especially important in people of 45 years or younger. ${ }^{14}$

This study found that dyslipidemia and diabetes has a protective factor against hemorrhagic stroke, it means dyslipidemia reduces the risk of hemorrhagic stroke compared with ischemic stroke. An inverse relationship between total serum cholesterol and low density lipoprotein cholesterol (LDL-C) and hemorrhages is being reported. ${ }^{15}$ Elevated serum cholesterol and stroke is not a well-established risk factor for stroke. Previous studies were confounded by the inverse association of total cholesterol and cerebral hemorrhage, but more recent trials are specific to ischemic stroke. ${ }^{7}$

Cholesterol and non-HDL cholesterol were associated with reduced trial in intracerebral haemorrhagic stroke, but this relation is poorly understood. Conversely, HDL cholesterol was associated with an increased risk of intracerebral haemorrhagic stroke. ${ }^{14,16}$ Previous study, showed that treatment with atorvastatin, male sex, increased age, haemorrhagic stroke as an entry event into the trial, and stage II hypertension at last visit before the haemorrhagic stroke were associated with incident haemorrhagic stroke. ${ }^{17}$ Another meta analysis study also recommends caution when considering statin therapy in patients with prior cerebral haemorrhage. $^{18}$

Diabetes is another well-established stroke risk factor. ${ }^{19}$ This study showed that proportion of diabetes in non-hemorrhagic stroke patients is significantly higher compared with hemorrhagic stroke patients $(68 \%)$ and $(32 \%)$ respectively (Table 1$)$. Previous study in Chinese population also had shown that diabetic patients were likely to have ischemic stroke and less likely to have haemorrhagic stroke (cerebral or subarachnoid) than non-diabetic patients. ${ }^{20}$ In more recent study it was also found that in the diabetic stroke population, small-vessel occlusion and large-artery atherosclerotic strokes occur with similar frequency. ${ }^{21}$
Age and sex were similar in both Group ischemic stroke and hemorrhagic stroke. This study also had shown that there is no significant effects of hemorrhagic stroke compared with ischemic stroke. Previous study found that the prevalence of stroke escalating for older individual in ischemic stroke and hemorrhagic stroke. ${ }^{7}$ The prevalence of common cardiovascular risk factors shows different age-specific patterns among various stroke subtypes. Recognition of these patterns may guide tailored stroke prevention efforts aimed at specific risk groups. ${ }^{22}$

There was also no significant difference in incident hemorrhagic stroke events between sexes. Female-specific characteristics increasing stroke risk include hypertensive disorder in pregnancy for ischemic stroke, late menopause and gestational hypertension for hemorrhagic stroke. Male-specific characteristics increasing stroke risk include medical androgen deprivation therapy for ischemic and any stroke and erectile dysfunction for any stroke. ${ }^{23}$

The limitation of this study was the use of case control method. We could not clarify the duration and sustainibility of treatment for each risk factor. We could not determine whether there was any difference betweeen the well controlled and uncontrolled risk factors. Further study were warraneted to show the benefit of well controlled risk facotrs.

\section{CONCLUSION}

Hypertension is the main risk factors for either hemorrhagic or non-hemorrhagic stroke. The proportion of hypertension in hemorrhagic stroke patients was significantly higher compared with non-hemorrhagic stroke patients. This study suggested that dyslipidemia could reduce the risk of hemorrhagic stroke, but it still requires further study to fully understand the mechanism. Age and sex had no significant effect. Diabetes was less commmon in hemorrhagic stroke patients. Hypertension, dyslipidemia, and diabetes are modifiable traditional vascular risk factors. By understanding about the risk factors and its management, we can set the best strategies to prevent both primary and secondary stroke.

\section{REFERENCES}

1. Murray CJ, Vos T, Lozano R, Naghavi M, Flaxman AD, Michaud C, et al. Disability-adjusted life years (DALYs) for 291 diseases and injuries in 21 regions, 1990-2010: a systematic analysis for the Global Burden of Disease Study 2010. Lancet 2012;380:2197-2223.

2. Strong K, Mathers $\mathrm{C}$ and Bonita R. Preventing stroke: saving lives around the world. Lancet Neurol 2007; 6:182-187.

3. World Health Organization. WHO Health statistics and 
information systems. http://www.who.int/healthinfo/global burden_disease/en/(assessed Aug 10, 2015).

4. Kim YD, Jung YH and Saposnikc G. Traditional risk factors for stroke in East Asia. Journal of Stroke 2016;18(3):273-285.

5. Romero JR, Morris $\mathrm{J}$ and Pikula $\mathrm{A}$. The traditional vascular risk factors are older age, hypertension, diabetes, heart disease/ atrial fibrillation, and dyslipidemia.: herapeutic Advances in Cardiovascular Disease. SAGE Publications 2008;2(4):287-303.

6. Smajlović D. Strokes in young adults: epidemiology and Prevention. Vascular Health and Risk Management 2015;11:157-164.

7. Grysiewicz RA, Thomas K and Dilip K. Pandey. Epidemiology of Ischemic and Hemorrhagic Stroke: Incidence, Prevalence, Mortality, and Risk Factors; Neurol Clin 2008;26:871-895.

8. Kirshner HS. Differentiating ischemic stroke subtypes: Risk factors and secondary Prevention. Journal of the Neurological Sciences 2009-04-15; 279 (1):1-8.

9. Dupont WD and Plummer WD. Power and Sample Size Calculations for Studies Involving Linear Regression. Elsevier 1998: 19(6):589-601.

10. DupontWD and Plummer WD Power and sample size calculations: A review and computer program. Elsevier 1990; 11(2):116-128.

11. Chen X, Zhou L, Zhang Y, Yi D, Liu L, Rao W, et al. Risk Factors of Stroke in Western and Asian Countries: A Systematic Review and Meta-analysis of Prospective Cohort Studies. BMC Public Health 2014; 14:776.

12. Redón J, Cea-Calvo L, Lozano JV, Martí-Canales JC, Llisterri $\mathrm{JL}$, Aznar J, et al. Investigators of the PREV-ICTUS study: Blood pressure and estimated risk of stroke in the elderly population of spain: the prev-ictus study. Stroke 2007; 38:1167-1173.

13. Wang J, Wen X, Li W, Li X, Wang Y and Lu W. Risk Factors for Stroke in the Chinese Population: A Systematic Review and Meta-Analysis. Journal of Stroke and Cerebrovascular Diseases 2017-03-01; 26(3):509-517.

14. O'Donnell MJ, Xavier D, Liu L, Zhang H, Chin SL, RaoMelacini $P$, et al. Risk factors for ischaemic and intracerebral haemorrhagic stroke in 22 countries (the INTERSTROKE study): a case-control Study. Lancet 2010-07-10; 376(9735): 112-123.

15. Cui R, Iso H, Toyoshima H, Date C, Yamamoto A, Kikuchi S, et al. Serum total cholesterol levels and risk of mortality from stroke and coronary heart disease in Japanese. The JACC study. Atherosclerosis 2007; 194(2):pp.415-20.

16. Blood cholesterol and vascular mortality by age, sex, and blood pressure: a meta-analysis of individual data from 61 prospective studies with 55000 vascular deaths. Lancet2007; 370: 1829-1839.

17. Goldstein LB, Amarenco P, Szarek M, Callahan A $3^{\text {rd }}$, Hennerici $\mathrm{M}$, Sillesen $\mathrm{H}$, et al: Hemorrhagic stroke in the Stroke Prevention by Aggressive Reduction in Cholesterol Levels study. Neurology 2008; 70: 2364-2370.

18. Amarenco $\mathrm{P}$ and Labeurche J. Lipid management in the prevention of stroke: review and updated meta-analysis of statins for stroke prevention. Lancet Neurol 2009; 8:453-63.

19. Adams RJ, Albers G, Alberts MJ, Benavente O, Furie K, Goldstein LB, et al. Update to the AHA/ASA recommendations for the prevention of stroke in patients with stroke and transient ischemic attack. Stroke 2008;39:1647-1652.

20. Zhang XD, Chen YR, Ge L, Ge ZM and Zhang YH; Features of stroke in Chinese diabetes patients: a hospital-based Study. The Journal of International Medical Research 2007; 35:540-546.

21. Ntaios G, Milionis $\mathrm{H}$, Vemmos $\mathrm{K}$, Makaritsis $\mathrm{K}$, Ferrari J, Strbian D, et al. Small-vessel occlusion versus large-artery atherosclerotic strokes in diabetics: Patient characteristics, outcomes, and predictors of stroke mechanism. European Stroke Journal 2016; 1(2):108-113.

22. Hauer AJ, Ruigrok YM, Algra A, van Dijk EJ, Koudstaal PJ, Luijckx GJ, et al. Age-Specific Vascular Risk Factor Profiles According to Stroke Subtype. Journal of the American Heart Association 2017;6(5).

23. Sturgeon JD, Folsom AR, Longstreth WT, Shahar E, Rosamond WD and Cushman M. Risk factors for intracerebral hemorrhage in a pooled prospective study. Stroke 2007;38(10):2718-2125.

\section{Authors Contribution:}

RP- Concept and design of the study, manuscript preparation, statistically analyzed and interpreted, critical revision of the manuscript; RDLRS - Concept and design of the Study, collected data, preparing first draft of manuscript, critical revision of manuscript and review of the study; ADW- Reviewed the literature,

preparing first draft of manuscript, and review of the study.

Orcid ID:

Dr. Rizaldy Taslim Pinzon: (D) http://orcid.org/0000-0002-3357-9907

Dr. Rosa De Lima Renita Sanyasi: (1) http://orcid.org/0000-0002-3616-6796

Dr. Andre Dharmawan Wijono: (D) http://orcid.org/0000-0001-7144-6104

Source of Support: Nil, Conflict of Interest: None declared. 